\title{
First Relapse
}

National Cancer Institute

\section{Source}

National Cancer Institute. First Relapse. NCI Thesaurus. Code C123399.

The reemergence of a disorder as diagnosed by clinical and/or laboratory evidence following a single documented period of remission. 